\title{
Ano-rectal Melanoma: A Rare Case Report
}

\author{
Ayesha Khatoon, Vyshnavi Vasantham, Urvashi Anil Sharma, Rupinder Kalra, Shakti Kumar Yadav, \\ Aarzoo Jahan, Sompal Singh, Namrata Sarin and Sonam Kumar Pruthi*
}

Department of Pathology, North Delhi Municipal Corporation Medical College and Hindu Rao Hospital, New Delhi, India.

\begin{abstract}
Ano-rectal melanoma is extremely rare and has dismal prognosis when compared to cutaneous melanomas.It presents as ano-rectal mass and patients usually complain of passing blood in stools. Being, ahighly aggressive neoplasm, widespread metastasis is common, which can be seen even at the time of diagnosis. Here, we present a case report of ano-rectal melanoma in a 40-year old male, who presented with complaints of anal growth since one month. Initially, a clinical diagnosis of rectal carcinoma was suspected. However, biopsy of the growth showed histomorphological features of melanoma, which wereconfirmed on immunohistochemistry
\end{abstract}

Keywords: Anorectal Melanoma, Immunohistochemistry, Biopsy

\section{Introduction}

Adenocarcinoma and squamous cell carcinomas are the most common anorectal malignancies. ${ }^{1,2}$ Ano-rectal region, though rare, is the third most common site of melanomas following skin and retina, and accounts for only $0.4 \%$ of all anal malignancies and less than $1 \%$ of all melanomas. ${ }^{3,4,5}$ Females in fifth or sixth decades of their life are most commonly affected. ${ }^{6}$ Patient presents with rectal bleeding, rectal mass, tenesmus or change in bowel habits. Surgical treatment modalities include wide local excision and abdominoperineal resection. Chemo-radiotherapy does not seem to improve overall survival rate and its role in anorectal melanoma needs further evaluation. We present an exceedingly rare case of anorectal melanoma, which was clinically diagnosed as rectal carcinoma.

\section{Case Report}

A 40-year-old male patient presented to surgical outpatient department with complaints of mass in ano-rectal region since one month. The patient had no significant past medical history. On per rectal examination, a firm polypoidal mass was noted at the ano-rectal region. Rest of the general physical and systemic examination were normal. Based on the examination findings, a clinical diagnosis of rectal carcinoma was suspected and a punch biopsy was taken from the growth and the same was received in histopathology department.

Biopsy tissue received in histopathology department, on gross examination, showed a single grey white to brown soft tissue piece measuring $2 \times 1.5 \times 0.3 \mathrm{~cm}$. Cut surface of the tumor was grey white to brown. Tissue was all processed and multiple sections on histopathological examination revealed a tumor comprising of tumor cells with epithelioid and spindle cell morphology. Epithelioid tumor cells had clear cytoplasm, pleomorphic round to oval nuclei, with some of them showing nuclear indentation and pigment in their cytoplasm. [Fig. 1, 2, 3] Numerous vascular channels were present in between these tumor cells along with focal areas of necrosis. [Fig. 4]

Immunohistochemical panel comprising of leukocyte common antigen (LCA), chromogranin, smooth muscle actin (SMA), cytokeratin, S-100 and Ki- 67 labelling index was applied. Tumor cells demonstrated S-100 positivity [Fig. 5] and were negative for LCA (leucocyte common antigen), chromogranin, SMA (smooth muscle antigen) and cytokeratin. Also, $\mathrm{Ki}-67$ labelling index was markedly high.

Based on histomorphological and immunohistochemical interpretation, a diagnosis of anorectal melanoma was made.

\section{Discussion}

Ano-rectal melanoma is an extremely rare and highly aggressive tumor, which was first described by Moore in 1857. ${ }^{7}$ Melanomas most commonly arise from skin, but can also be found in retina and other non-cutaneous mucosal sites like vagina and head and neck with anorectum being the third most common site of mucosal melanomas. ${ }^{8}$ Incidence rate of anorectal melanoma amongst all melanomas is 0.4 to $3 \%$ and they comprise of 0.1 to $0.6 \%$ of all anorectal malignancies. ${ }^{3,4,9}$

Common clinical presentation includes rectal bleeding, change in bowel habits, ano-rectal pain or rectal mass. Hence, it can be misdiagnosed clinically as haemorrhoids, skin tag or ulcers..$^{10}$

Grossly, the tumor appears polypoidal with or without pigmentation. Four histological cell types have been reported, which include spindle, epithelioid, lymphoma 


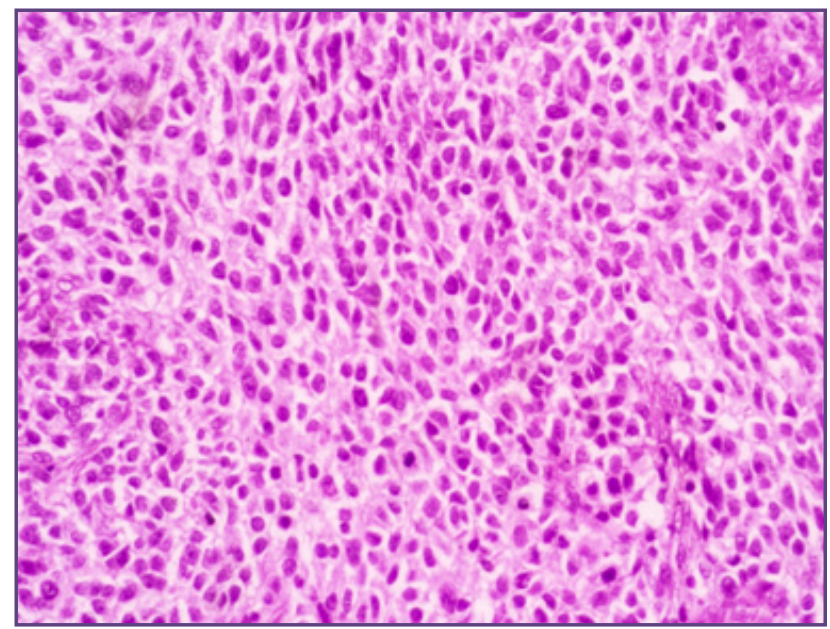

Fig. 1: Epithelioid tumor cells with clear cytoplasm and round to oval pleomorphic nuclei (H\&E 400X).

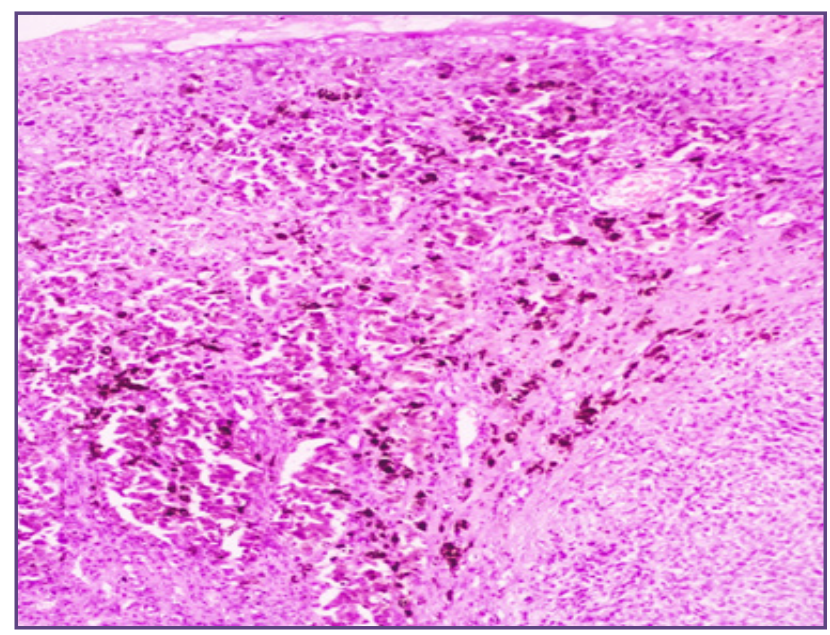

Fig. 3: Tumor cells demonstrate cytoplasmic pigment (H\&E 400X).

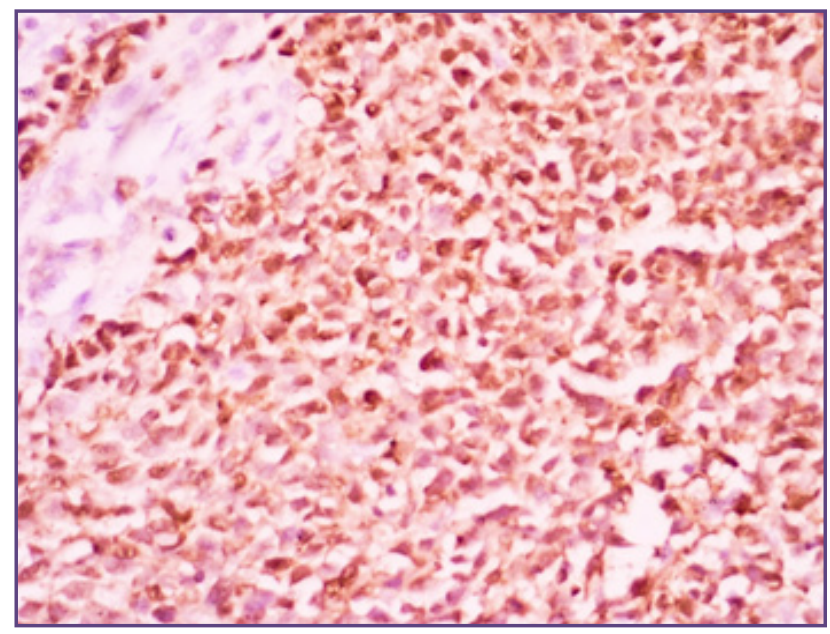

Fig. 5: Diffuse cytoplasmic and nuclear staining of tumor cells for S-100 protein (DAB 400X).

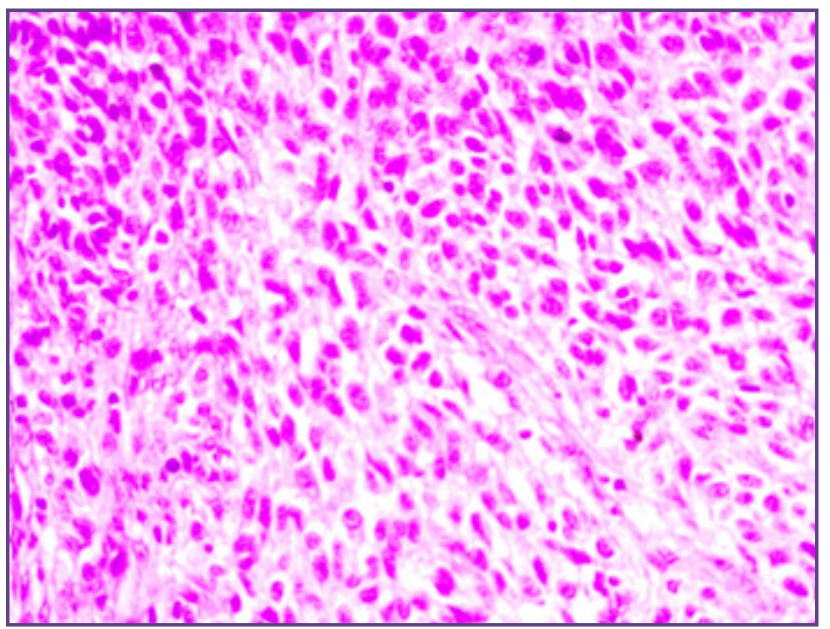

Fig. 2: Epithelioid and spindle shaped tumor cells showing pleomorphic hyperchromatic nuclei (H\&E 400X).

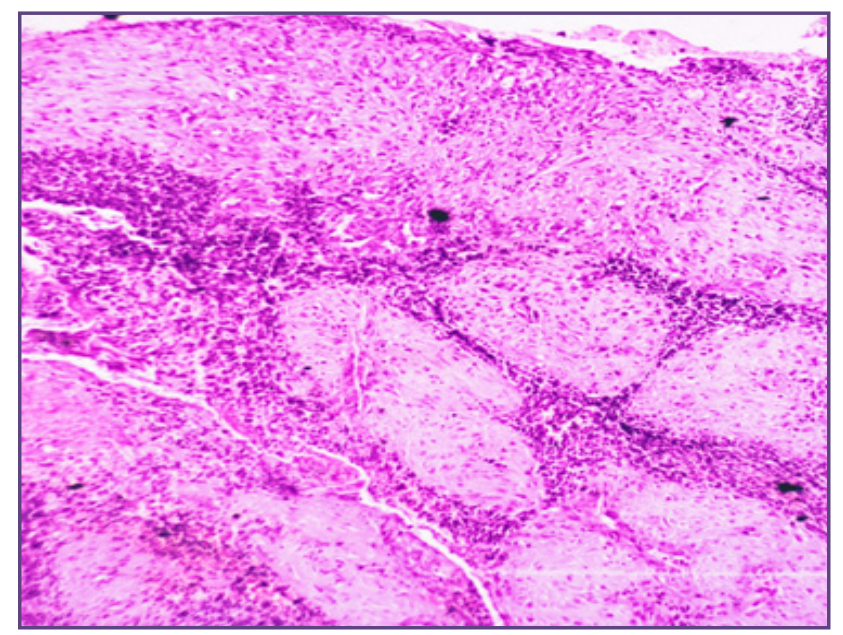

Fig. 4: Epithelium with focal areas of necrosis, inflammatory cell infiltrate and numerous vascular channels (H\&E 100X)

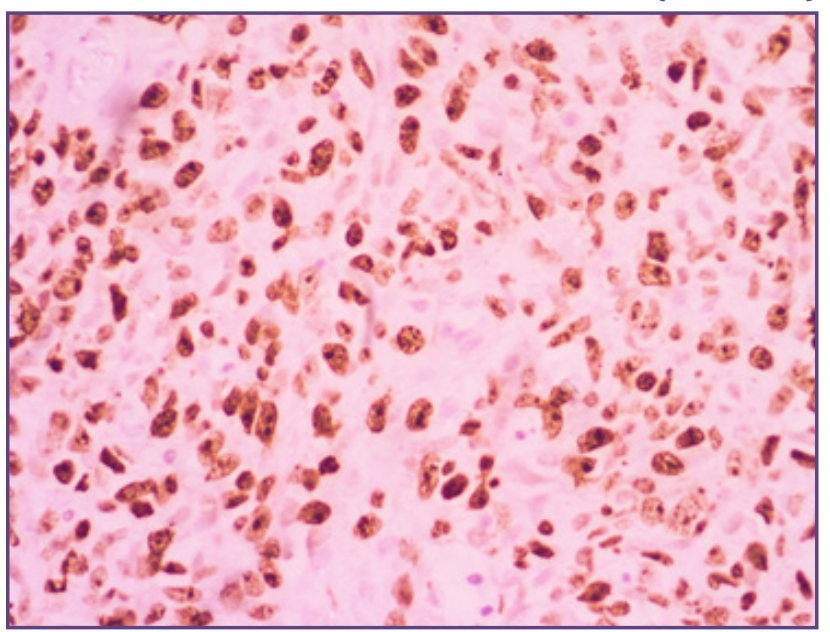

Fig. 6: Ki-67 labelling index in melanoma cells (DAB 400X). 
like and pleomorphic. ${ }^{11}$ In our case, epithelioid and spindle cell types of tumor cell population were found.

$30 \%$ of anorectal melanomas are amelanotic ${ }^{12,13}$ and thus, it can be misdiagnosed as lymphoma, undifferentiated carcinoma, poorly differentiated squamous cell carcinoma and adenocarcinoma on morphology. ${ }^{14}$

A comprehensive immunohistochemical panel that is useful for confirmative diagnosis include S-100, Melan-A, Ki-67 labelling index and HMB-45. ${ }^{11}$ In our case, tumor cells were positive for S-100 and Ki-67 labelling index was markedly high.

Owing to its rarity and misdiagnosis with conditions like haemorrhoids, ulcers, skin tags, the treatment is delayed which may result in metastatic disease, even at the time of diagnosis. ${ }^{15,16}$ Most common site of metastasis includes liver, lung, pelvis or brain. PET scan is useful for staging of anorectal melanoma

Surgical treatment for ano-rectal melanoma includes complete resection of tumor which can be done either by sphincter sparing wide local excision (WLE) or by abdominoperineal resection (APR), with the later being performed in patients where WLE is not feasible. ${ }^{10}$

The 5-year survival rate is as low as $6 \% .{ }^{17}$ Longer survival rate is seen in patients with tumors showing low Ki-67 labelling index ${ }^{18}$

\section{Conclusion}

Ano-rectal melanoma, although an extremely rare entity, clinicians and pathologists must be aware of its varied clinical and morphological spectrum and the diagnostic difficulties associated with it. It warrants an early diagnosis as the lesion can be easily misdiagnosed clinically as haemorrhoids, due to its non-specific symptoms of tenesmus, anorectal mass, discharge and/ or itching. It being an aggressive neoplasm, initial presentation can even be a metastatic disease.

\section{References}

1. Van Shaik PM, Ernst MF, Meijer HA, Bosscha K. Melanoma of the rectum: a rare entity. World J Gastroenterol 2008;14:1633-5.

2. Reid A, Dettrick A, Oakenful C, Lambrianides AL. Primary rectal melanoma. JCSR 2011;11:2.

3. Chang AE, Karnell LH, Menck HR. The National Cancer Data Base report on cutaneous and noncutaneous melanoma: a summary of 84,836 cases from the past decade. The American College of Surgeons Commission on Cancer and the American Cancer Society. Cancer 1998; 83:1664-1678.

4. Zhang S, Gao F, Wan D. Effect of misdiagnosis on the prognosis of anorectal malignant melanoma. J Cancer Res Clin Oncol 2010; 136:1401-1405.

5. Dominiak NR, Wick M, Smith T. Mucosal melanomas: Sitespecific information, comparisons with cutaneous tumors, and differential diagnosis. Sem Diag Path 2016; 33: 191-7.

6. Correia M, Amonkar D, Ramani A, Desousa R. Anal melanoma-a case report and review of literature. Internet $\mathrm{J}$ Surg. 2009;19:13.

7. Morson BC, Volkstadt H. Malignant melanoma of the anal canal. J Clin Path 1963; 16:126.

8. Postow MA, Hamid O, Carvajal RD. Mucosal Melanoma: Pathogenesis, Clinical Behavior, and Management. Curr Oncol Rep (2012) 14:441-448.

9. Thibault C, Sagar P, Nivatrongs S, Ilstrup DM, Wolff BE.Anorectal melanoma--an incurable disease? Dis Colon Rectum. 1997; 40: 661-668.

10. Singer M, Mutch MG. Anal melanoma. Clin Colon Rectal Surg. 2006;19:78-87.

11. Chute DJ, Cousar JB, Mills SE. Anorectal malignant melanoma: morphologic and immunohistochemical features. Am J Clin Pathol. 2006;126:93-100Hillenbrand A, Barth TF, Henne-Bruns D, Formentini A. Anorectal amelanotic melanoma. Colorectal Dis. 2008;10:612-615.

12. Banerjee SS, Harris M. Morphological and immunophenotypic variations in malignant melanoma. Histopathology. 2000;36:387-402.

13. Hillenbrand A, Barth TF, Henne-Bruns D, Formentini A: Anorectal amelanotic melanoma. Colorectal Dis 2008;10:612-615.

14. Gatter KC, Ralfkiaer E, Skinner J, et al. An immunocytochemical study of malignant melanoma and its differential diagnosis from other malignant tumors. J Clin Pathol. 1985;38:1353-1357.

15. Olinici CD, Muntean IL, Resiga LI, Crişan DO. Anorectal melanoma. Case report and review of the literature. Rom J Morphol Embryol. 2007;48(3):299-302.

16. Negbenebor NA, Edward Feller MD. A rare case of amelanotic anorectal melanoma. Rhode Island Medical Journal. 2017 Sep 1;100(9):31.

17. Patrick RJ, Fenske NA, Messina JL. Primary Mucosal Melanoma. J Am Acad Derm 2007; 56 (5): 828-34

18. Ben-Izhak O., Bar-Chana M.,Sussman L., Dobiner V., Sandbank J., Cagnano M., Cohen H., Sabo E., Ki67 antigen and PCNA proliferation markers predict survival in anorectal malignant melanoma, Histopathology, 2002, 41(6):519-525.

*Corresponding author:

Dr. Sonam Kumar Pruthi, Specialist. Department of Pathology, North Delhi Municipal Corporation Medical College and

Hindu Rao Hospital, New Delhi, India.

Email: sonam_manipal@yahoo.com

Date of Submission : 15/01/2020

Financial or other Competing Interests: None. 